\title{
Spatial frequency comparisons of rotated gratings
}

\author{
DUANE O. BOWKER and LINDSAY T. SHARPE \\ Center for Visual Science, University of Rochester, Rochester, New York 14627
}

\begin{abstract}
Reaction time for determining if two square-wave gratings are the same or different is a bimodal function of the relative angular separation (RAS) between them. Response time peaks at $60^{\circ}$ and $120^{\circ}$ separation and drops significantly at approximately $90^{\circ}$, provided that the gratings being compared are of the same spatial frequency. This pattern of results is not in line with those previously reported for more complex figures, nor may it be attributed to any "oblique effect," since the same function is obtained with the comparison gratings placed at different retinal orientations. One possible explanation is that orthogonally tuned orientation channels interact in a facilitatory fashion in the human visual system.
\end{abstract}

Subjects' reaction time (RT) for determining if two stimuli are the same or different is a linearly increasing function of the relative angular separation (RAS) between the stimuli (Cooper \& Shepard, 1973; Metzler \& Shepard, 1974; Shepard \& Metzler, 1971). RT increases as the stimuli are rotated apart from $0^{\circ}$ to $180^{\circ}$ and then decreases as the stimuli are further rotated from $180^{\circ}$ to $360^{\circ}$. This linear relationship has been demonstrated for two-dimensional (Cooper, 1975) and three-dimensional (Shepard \& Metzler, 1971) random forms, for stick-figures (Hochberg \& Gellman, 1977), and for letters (Cooper \& Shepard, 1973). On the basis of these and other results, some investigators argue that subjects are generating internal representations of the stimuli and then transforming these representations by an analog process (Kosslyn \& Pomerantz, 1977; Shepard \& Metzler, 1971). Once the subject has "mentally rotated" the two stimuli into congruence, he can decide whether or not they are similar. Underlying this interpretation is the assumption that the rotation is always carried out in the shortest possible direction; an assumption supported by the finding that the RT function is generally symmetric about $180^{\circ}$ RAS for nonsymmetrical figures (i.e., those figures with $360^{\circ}$ of possible rotation). For symmetrical figures, such as square-wave gratings, the function should peak at $90^{\circ}$, the maximum possible RAS. This is because square-wave gratings have only $180^{\circ}$ possible rotation. We tested this prediction by having subjects make spatial frequency comparisons of equal-contrast square-wave gratings.

We wish to express our appreciation to $\mathrm{Dr}$, Ola Selnes for his assistance in the stimulus production, to Dr. Michael Davidson and $\mathrm{Mr}$. Jerome Toporek for their assistance in the data analysis procedures, and to Drs. Ralph N. Haber and Robert M. Chapman for their careful criticisms of the original manuscript. This research was supported by Grant EY-01319, awarded by the National Eye Institute.

\section{METHOD}

\section{Subjects}

The subjects included the two authors plus seven undergraduate students who volunteered from introductory psychology courses at the University of Rochester. All of the volunteers were naive with respect to the experimental hypothesis. Four subjects were male; five were female. Their mean age was approximately 21 years, and all were right-handed. All subjects reported that they had $20 / 20$ visual acuity, either with corrective lenses or without them.

\section{Stimuli}

Stimuli were photographic reproductions of an equal-duty-cycle, square-wave grating transparency. The transparency was mounted in an Auto-focus Enlarger D-3 (Omega Corporation), which permitted the emulsion-transparency distance to be continuously varied. By careful manipulation of this distance, a series of different spatial-frequency gratings were produced. Spatial frequency was defined as the number of cycles of a repetitive grating pattern per degree of visual angle. The grating photographs were cut up into $7.6-\mathrm{cm}$-diam disks and mounted on specially constructed cards appropriate for tachistoscopic presentation. These cards were designed so that the grating patterns could be rotated by fixed amounts, thereby permitting the angular orientation of the grating bars to be changed. Each card contained two grating disks, $3.8^{\circ}$ in diameter, which were separated horizontally by $4.2^{\circ}$ from center to center (see Figure 1). On the basis of preliminary investigations, 12 pairs of grating disks were selected. They were made up of the following spatial frequencies calculated for a viewing distance of $86.36 \mathrm{~cm}: 2.45,3.01,3.88,4.75$, and $6.12 \mathrm{c} / \mathrm{deg}$. On four of the cards, the pairs were of the same spatial frequency, $3.01,3.88,4.75$, or $6.12 \mathrm{c} / \mathrm{deg}$; on the other eight, the pairs were adjacently sampled spatial frequencies, $2.45 / 3.01,3.01 / 3.88,3.88 / 4.75$, or $4.75 / 6.12 \mathrm{c} / \mathrm{deg}$, half with the finer grating on the right, half with it on the left. The frequency ratio of the different existing pairs varied between 1.22 and 1.29, easily within the observer's ability to discriminate (Campbell, Nachmias, \& Jukes, 1970). The contrast of the gratings was approximately $45 \%$. (Contrast is defined as: I $\max -I \mathrm{~min} / \mathrm{I} \max$ + I min: where I $\max =$ luminance of the light bars of the grating and I $\min =$ luminance of the dark bars.) Luminance was measured with a Spectra Spotmeter (Hoffman Engineering Corp.).

\section{Procedure}

The stimuli were presented in a three-channel tachistoscope (Gerbrands T-3B-1). In one channel, a fixation cross was displayed 


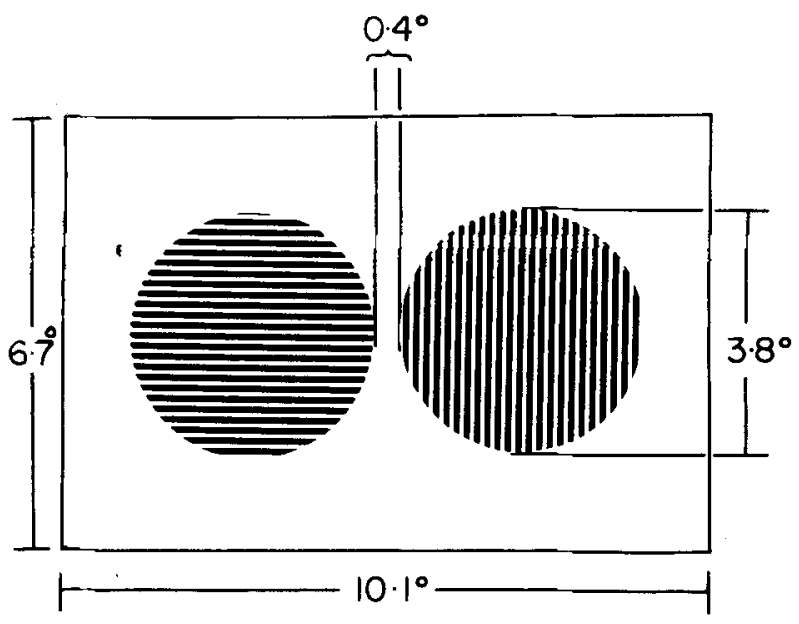

Figure 1. Stimulus dimensions in degrees of visual angle. Grating on the Jeft is arbitrarily defined as the "reference" grating, presented at $0^{\circ}, 45^{\circ}, 90^{\circ}$, ar $135^{\circ}$ retinal orientation. Grating on the right is the "test" grating, presented at $0^{\circ}, 20^{\circ}, 40^{\circ}, 60^{\circ}, 80^{\circ}$, $90^{\circ}, 100^{\circ}, 120^{\circ}, 140^{\circ}$, or $160^{\circ}$ angular separation relative to the reference grating. Actual stimuli were presented against a black matte background.

at a luminance of $8.22 \mathrm{~cd} / \mathrm{m}^{2}$. It was positioned so that upon stimulus presentation, the subject's fixation would be centered between the two grating disks. The cross was displayed continuously until the grating stimuli were presented in the second channel. The gratings, viewed at a distance of $86.36 \mathrm{~cm}$, were displayed at a space-average luminance of $4.80 \mathrm{~cd} / \mathrm{m}^{2}$ against a black matte background of $.86 \mathrm{~cd} / \mathrm{m}^{2}$. Subjects viewed the stimuli binocularly through natural pupils.

During each trial, the subjects were instructed to fixate on the cross. Stimulus cards were then shown for a duration of $3,000 \mathrm{msec}$, within which time they were required to determine if the two gratings were of the same or different spatial frequency. Subjects indicated their decisions by pressing one of the two handheld switches: the "same" switch held in the right hand and the "different" switch held in the left hand. Depressing either switch stopped a millisecond timer (ERC-Textron Corp.) which recorded the subject's reaction time.

The subjects were instructed to make their size judgments independent of the grating orientations. The leftmost grating, the reference grating, was presented at four different retinal orientations: $0^{\circ}, 45^{\circ}, 90^{\circ}$, and $135^{\circ}$. The grating on the right was presented at 10 different orientations relative to the grating on the left: $0^{\circ}, 20^{\circ}, 40^{\circ}, 60^{\circ}, 80^{\circ}, 90^{\circ}, 100^{\circ}, 120^{\circ}, 140^{\circ}$, and $160^{\circ}$. These differences in relative orientation defined the main factor of RAS.

Prior to the start of the experiment, the subjects were given 40 practice trials to familiarjze them with the experimental procedure and to stabilize their response latencies. Haif of these triais required a same response; half a different response. The subjects were immediately informed of any errors in judgment. Following the practice trials, 160 test trials were given during which response latencies were recorded. These trials were randomly arranged so that subjects viewed equal numbers of each response condition, each spatial frequency comparison, each RAS, and each reference grating orientation. The entire session typically lasted between $1-1.25 \mathrm{~h}$. The subjects were permitted a short break halfway through the test session.

\section{RESULTS}

A repeated measures analysis of variance of the response times was conducted to determine the treatment effects of the factorialized variables: response (same vs. different), absolute orientation of the leftmost grating, orientation of the rightmost grating relative to the leftmost grating (RAS), and spatial frequency of the gratings used in the comparison. Response, absolute orientation, and RAS were factorially independent, but the spatial frequency comparison factor was nested in the main effect of response; i.e., subjects were only correct in responding "same" when shown those cards containing pairs of the same spatial frequency gratings. Incorrect responses and responses greater than $3,000 \mathrm{msec}$ were excluded from the data analysis.

The results of the ANOVA, summarized in Table 1, indicate that all main effects were highly significant sources of variance except for the absolute orientation of the reference (leftmost) grating. This factor also failed to interact significantly with any of the other variables, indicating that the reference grating

Table 1

Summary Table of the Analysis of Variance of the Response Times

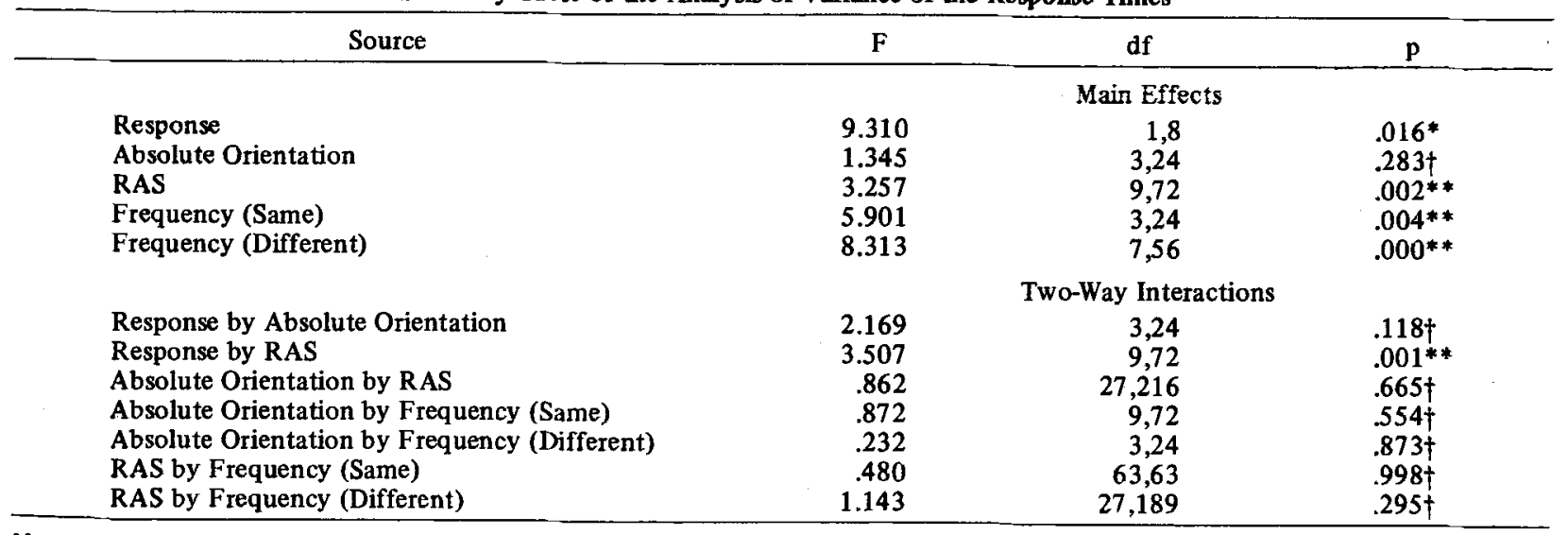

Note-Three-way interactions of Response by RAS by Absolute Orientation, RAS by Absolute Orientation by Frequency (same), and RAS by Absolute Orientation by Frequency (different) could not be performed using all nine subjects since some subjects were missing entire cells. An ANOVA on five of the subjects with complete cells showed no significant three-way interactions.

${ }^{*} p<.05, \quad * * p<.01$. +Nonsignificant. 


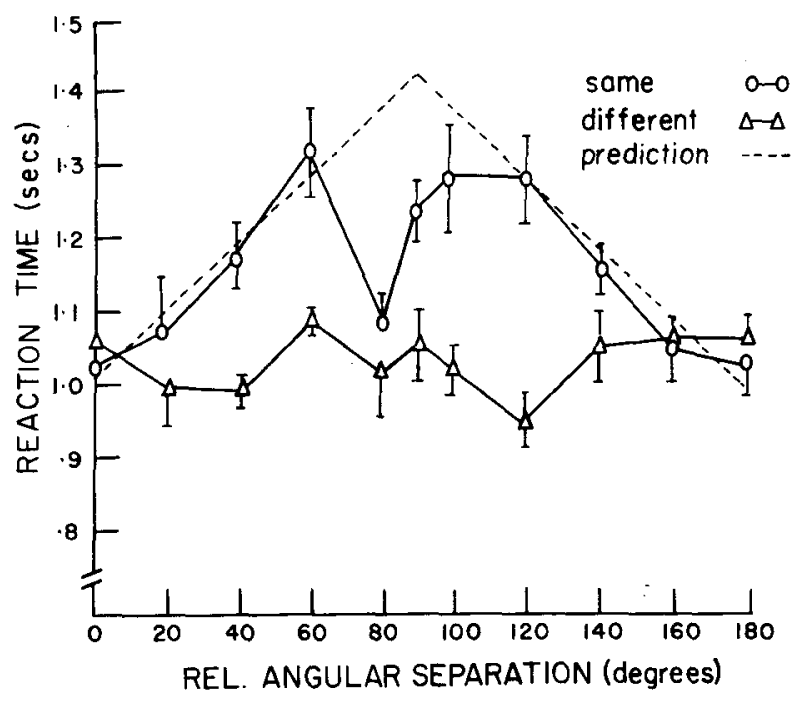

Figure 2. Mean reaction times for determining whether pairs of grating stimuli were the same or different in spatial frequency: open circles, same responses; open triangles, different responses. Each data point represents the mean of trials across nine subjects. On the basis of previous investigations involving rotational comparisons of more complex stimuli, our results were expected to resemble the dotted function, being a symmetrical linear function peaking at $90^{\circ}$ relative angular separation. The actual shape of the predicted function has been derived by making a least-squares fit to the first four points of the "same" function on either side $0^{\circ} / 180^{\circ}$. Error bars represent standard error of the mean.

orientation had no effect upon reaction time judgments. Perhaps the most interesting result contained in Table 1 is the highly significant interaction between RAS and response $(p<.005)$. This relationship, depicted graphically in Figure 2, was analyzed by Tukey's honestly significant difference procedure (Kirk, 1968), which revealed two interesting features about the interaction. First, changes in response latency occurred only as a systematic function of RAS for "same" judgments and not for "different" judgments (post hoc comparisons are summarized in Table 2). Second, the longest reaction time for "same" judgments did not occur at $90^{\circ}$ as was predicted, but at $60^{\circ}$ and $120^{\circ}$ RAS. Furthermore, responses at $60^{\circ}$ and $120^{\circ}$ were not only significantly longer than those at $0^{\circ} / 180^{\circ}$, but also significantly longer than those at $80^{\circ}$ RAS, where a drop in the RT/RAS function is clearly evident in Figure 2. (The mean reaction times at this drop are not significantly different from those at $0^{\circ}$.) This drop is consistent across all orientations of the leftmost grating and all spatial frequencies of the grating pairs.

An examination of the mean reaction times for the various spatial frequencies did not reveal any consistent trend. This is contrary to several reports that higher spatial frequencies produce longer reaction times (Breitmeyer, 1975; Lupp, Hauske, \& Wolf, 1976; Vassilev \& Mitov, 1976). The discrepancy is probably due to the different tasks employed, theirs being a simple detection task, whereas ours was a more involved discrimination task. On the other hand, octave difference in the grating pairs accounted for a significant amount of the variance between the "different" grating pairs $(15 \%)$. Again, the main effect of frequency, though significant, failed to interact in any way with the other factors.

Subjects had an overall error rate of $7.8 \%$ in the task. "Same" trials produced a somewhat lower error rate than "different" trials $(6.7 \%$ vs. $9.0 \%)$ and error rate seemed to display the same relationship to RAS as did reaction time for the "same" responses (Figure 3).

\section{DISCUSSION}

Why did subjects judge frequency differences between gratings faster when the gratings were nearly orthogonal to one another than when they were separated by less acute angles? This is contrary to our prediction that the longest RT should occur at the largest RAS. The visual system's reduced sensitivity to oblique orientations (Appelle, 1972; Campbell, Kulikowski, \& Levinson, 1966) cannot be directly responsible because the effect occurred independently of the retinal orientation of the reference grating. However, anistropies of the visual system may result in an indirect oblique effect since visual stimuli are apparently perceived differently when presented in different retinal orientations. For instance, oblique

Table 2

Summary Table of the Post Hoc Analysis of the Response Times for Various Relative Angular Separations (RAS)

\begin{tabular}{|c|c|c|c|c|c|c|c|c|c|c|c|c|c|c|c|c|c|c|c|}
\hline \multicolumn{10}{|c|}{ Post Hoc RAS (Different) } & \multicolumn{10}{|c|}{ Post Hoc RAS (Same) } \\
\hline & 20 & 40 & 60 & 80 & 90 & 100 & 120 & 140 & 160 & & 20 & 40 & 60 & 80 & 90 & 100 & 120 & 140 & 160 \\
\hline $\begin{array}{r}0 \\
20 \\
40 \\
60 \\
80 \\
90 \\
100 \\
120 \\
140\end{array}$ & n.s. & $\begin{array}{l}\text { n.s. } \\
\text { n.s. }\end{array}$ & $\begin{array}{l}\text { n.s. } \\
\text { n.s. } \\
\text { n.s. }\end{array}$ & $\begin{array}{l}\text { n.s. } \\
\text { n.s. } \\
\text { n.s. } \\
.01\end{array}$ & $\begin{array}{c}\text { n.s. } \\
\text { n.s. } \\
\text { n.s. } \\
\text { n.s. } \\
.01\end{array}$ & $\begin{array}{l}\text { n.s. } \\
\text { n.s. } \\
\text { n.s. } \\
\text { n.s. } \\
\text { n.s. } \\
\text { n.s. }\end{array}$ & $\begin{array}{l}\text { n.s. } \\
\text { n.s. } \\
\text { n.s. } \\
.01 \\
\text { n.s. } \\
\text { n.s. } \\
\text { n.s. }\end{array}$ & $\begin{array}{l}\text { n.s. } \\
\text { n.s. } \\
\text { n.s. } \\
\text { n.s. } \\
\text { n.s. } \\
\text { n.s. } \\
\text { n.s. } \\
\text { n.s. }\end{array}$ & $\begin{array}{l}\text { n.s. } \\
\text { n.s. } \\
\text { n.s. } \\
\text { n.s. } \\
\text { n.s. } \\
\text { n.s. } \\
\text { n.s. } \\
\text { n.s. } \\
\text { n.s. }\end{array}$ & $\begin{array}{r}0 \\
20 \\
40 \\
60 \\
80 \\
90 \\
100 \\
120 \\
140\end{array}$ & n.s. & $\begin{array}{l}\text { n.s. } \\
\text { n.s. }\end{array}$ & $\begin{array}{l}.01 \\
.01 \\
.01\end{array}$ & $\begin{array}{c}\text { n.s. } \\
\text { n.s. } \\
\text { n.s. } \\
.01\end{array}$ & $\begin{array}{l}.01 \\
.01 \\
\text { n.s. } \\
\text { n.s. } \\
.01\end{array}$ & $\begin{array}{c}.01 \\
.01 \\
\text { n.s. } \\
\text { n.s. } \\
\text { n.s. } \\
\text { n.s. }\end{array}$ & $\begin{array}{l}.01 \\
.01 \\
.01 \\
\text { n.s. } \\
.01 \\
\text { n.s. } \\
\text { n.s. }\end{array}$ & $\begin{array}{l}.01 \\
\text { n.s. } \\
\text { n.s. } \\
\text { n.s. } \\
\text { n.s. } \\
\text { n.s. } \\
\text { n.s. } \\
\text { n.s. }\end{array}$ & $\begin{array}{l}\text { n.s. } \\
\text { n.s. } \\
\text { n.s. } \\
.01 \\
\text { n.s. } \\
.01 \\
.01 \\
.01 \\
\text { n.s. }\end{array}$ \\
\hline
\end{tabular}

Note-Entries indicate significance level using Tukey's HSD procedure (Kirk, 1968). 


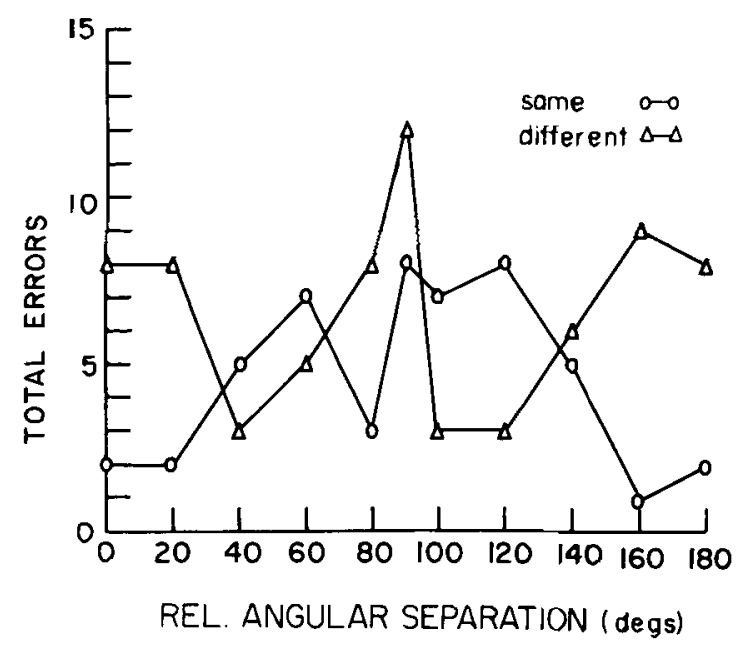

Figure 3. Tolal errors accumulated across all subjects as a function of relative angular separation. Each point is out of possible 72 trials.

lines appear longer (Caelli, 1977; Pollack \& Chapanis, 1952; Shipley, Nann, \& Penfield, 1949) and have a lower contrast sensitivity (Campbell, Kulikowski, \& Levinson, 1966) than their vertical and horizontal counterparts. Possibly, then, pairs of grating stimuli presented in the same or orthogonal orientations appear more alike than those presented at other relative orientations, resulting in a facilitation effect for such comparisons. This argument is supported by the relationship error rate bears to RAS (Figure 3).

A second explanation is that there may be some interaction between orthogonally tuned orientation channels in the human visual system. Indeed, other psychophysical evidence supports this notion. For instance, angle-contingent color aftereffects generalize more strongly to right angles than to the adaptation angle (White \& Riggs, 1974). Tilt aftereffects (Gibson \& Radner, 1937; Morant \& Harris, 1965) and simultaneous tilt effects (O'Toole \& Wenderoth, 1977; Tolhurst \& Thompson, 1975) produce perceptual distortions not only about the adaptation orientation but also about orientations $90^{\circ}$ away. Afterimages for bars $90^{\circ}$ apart may interact even when temporal delays are introduced between the onset of the afterimage of one bar and that of the delayed bar (Atkinson, 1973). There is also a scant amount of physiological data suggesting such orthogonal interactions (Hubel \& Wiesel, 1965; Rocha-Miranda, Linden, Volchan, Lent, \& Bombardier, 1976). Hubel and Wiesel (1965), for instance, report having found units in Area 19 of the cat which prefer right-angled stimuli. These cells were found predominantly in columns in which not all cells responded to the same orientation but had their selectivities distributed among two orientations orthogonal to one another. Both these orientations were required to maximally excite this special class of "higher order hypercom- plex" cell, suggesting a possible convergence of the lower order neurons onto them.

Whether or not these higher order cells are indeed responsible for the effects reported here is uncertain. Although other authors have attributed psychophysical effects of orthogonal interactions to such units (Coltheart, 1971; White \& Riggs, 1974), we feel that their conclusions are somewhat premature based on the small amount of physiological data currently available on these units.

A complete explanation of our results must explain not only the nonmonotonicity of the "same" function, but also why "same" comparisons generate a differently shaped function from that generated by the "different" comparisons, an atypical finding in mental rotation studies (Cooper, 1975; Shepard \& Metzler, 1971). We have tried various ways of explaining this anomaly. One explanation involves conceptualizing the visual system as a two-dimensional neural array (Maffei \& Fiorentini, 1977) containing channels responding selectively to particular combinations of orientation and spatial frequency. Given the nature of the task in this experiment, the visual system is particularly sensitive to the differential activation of channels in the spatial frequency dimension. The interpretation of this pattern of activity may be thought of as being handled by a central decision processor. When there is a sufficiently large spread of excitation among the spatial frequency channels, the processor immediately outputs "different" without checking the orientation dimension. Its decision is rapid and relatively independent of angular separation. When, however, the spread of excitation along the spatial frequency dimension is less than the critical amount for immediate discrimination, the processor must check the orientation dimension. A small amount of spread along the orientation dimension as well as the spatial frequency dimension will cause it to output "same." A large amount of spread along the orientation dimension, however, will cause it to generate an internal rotational transformation in order to match the orientations of the stimuli (i.e., to reduce the spread of excitation in the orientation dimension). This transformation is probably an analog process that takes more time for greater angular separations. If, following this transformation, the spread of excitation in the spatial frequency dimension is still below the critical value, the processor outputs "same." If not, it outputs "different." Such a model would explain the monotonically rising portion of the "same" function in Figure 2, and would also explain why the values are generally higher than those of the "different" function.

No doubt there are several other such models which could be advanced to explain our results, including the "indirect oblique effect" mentioned above. Further experiments based on theoretical predictions will have to be conducted to evaluate the 
relative soundness of such models. At any rate, it does appear that some sort of interesting interaction is occurring with orthogonally oriented stimuli.

\section{REFERENCES}

ATkinson, J. Properties of human visual orientation detectors: A new approach using patterned afterimages. Journal of Experimental Psychology, 1973, 98, 55-63.

Appelle, S, Perception and discrimination as a function of stimulus orientation: The "oblique effect" in man and animals. Psychological Bulletin, 1972, 78, 266-278.

Breitmeyer, B. G. Simple reaction time as a measure of the temporal response properties of transient and sustained channels. Vision Research, 1975, 15, 1411-1412.

CaElli, T. Is perceived length affected by interactions between orientation detectors? Vision Research, 1977, 17, 837-841.

Campbell, F. W., Kulikowski, J. J., \& Levinson, J. The effect of orientation on the visual resolution of gratings. Journal of Physiology, 1966, 187, 427-436.

Cam PBell, F. W., Nachmias, J., \& Jukes, J. Spatial frequency discrimination in human vision. Journal of the Optical Society of America, 1970, 60, 555-559.

Colthenet, M. Visual feature-analyzers and after-effects of tilt and curvature. Psychological Review, 1971, 78, 114-121.

Cooper, L. A. Mental rotation of random two-dimensional shapes, Cognitive Psychology, 1975, 7, 20-43.

CoOper, L. A., \& ShePARd, R. N. The time required to prepare for a rotated stimulus. Memory \& Cognition, 1973, 1, 246-250.

Gibson, J. J., \& Radner, M. Adaptation, after-effect and contrast in the perception of tilted lines. I. Quantitative studies. Journal of Experimental Psychology, 1937, 20, 453-469.

Hochвекg, J., \& Gellman, L. The effect of landmark features on mental rotation times. Memory \& Cognition, 1977, 5, 23-26.

Hubel., D. H., \& Wiesel, T. N. Receptive fields and functional architecture in two nonstriate visual areas (18 and 19) of the cat. Journal of Neurophysiology, 1965, 28, 229-289.

KInk, R. E. Experimental design: Procedures for the behavioral sciences. Monterey, Calif: Brooks/Cole, 1968.
Kosslyn, S. M., \& Pomerantz, J. R. Imagery, propositions and the form of internal representations. Cognitive Psychology, $1977,9,52-76$.

Lupp, U., Hauske, G., \& Wolf, W. Perceptual latencies to sinusoidal gratings. Vision Research, 1976, 16, 969-972.

Maffei, L., \& Fionentini, A. Spatial frequency rows in the striate visual cortex. Vision Research, 1977, 17, 257-264.

Metzler, J., \& Shepard, R. N. Transformationai studies of the internal representation of three-dimensional objects. In R. L. Solso (Ed.). Theories in cognitive psychology: The Loyola Symposium. New York: Wiley, 1974.

Morant, R. B., \& HaRRis, J. R. Two different aftereffects of exposure to visual tilts. American Journal of Psychology, 1965, 78, 218-226.

O'Toole, B., \& Wenderoth, P. The tilt illusion: Repulsion and attraction effects in the oblique meridian. Vision Research, $1977,17,367-374$.

Pollack, W. T., \& Chapanis, A. The apparent length of a line as a function of its inclination. Quarterly Journal of Experimental Psychology, 1952, 4, 170-178.

Rocha-Miranda, C. W., Linden, R., Volchan, E., Lent, R., $\&$ Bombardier, R. A. Receptive field properties of single units in the opossum striate cortex. Brain Research, 1976, 104, 197-219.

ShePARd, R. N., \& Metzler, J. Mental rotation of threedimensional objects. Science, 1971, 171, 701-703.

Shipley, W. C., Nann, B. M., \& Penfield, M. J. The apparent length of tilted lines. Journal of Experimental Psychology, $1949,39,548-551$.

Tolmurst, D. J., \& Thompson, P. G. Orientation illusions and aftereffects: Inhibition between channels. Vision Research, $1975,15,967-972$.

Vassilev, A., \& Mitov, D. Perception time and spatial frequency. Vision Research, 1976, 16, 89-92.

White, K. D., \& Rigas, L. A. Angle-contingent color aftereffects. Vision Research, 1974, 14, 1147-1154.

(Received for publication December 14, 1978; revision accepted June 5, 1979.) 